\title{
Blast waves from violent explosive activity at Yasur Volcano, Vanuatu
}

\author{
E. Marchetti, ${ }^{1}$ M. Ripepe,${ }^{1}$ D. Delle Donne, ${ }^{1,2}$ R. Genco, ${ }^{1}$ A. Finizola, ${ }^{3}$ and E. Garaebiti ${ }^{4}$ \\ Received 4 September 2013; revised 25 October 2013; accepted 30 October 2013.
}

[1] Infrasonic and seismic waveforms were collected during violent strombolian activity at Yasur Volcano (Vanuatu). Averaging 3000 seismic events showed stable waveforms, evidencing a low-frequency $(0.1-0.3 \mathrm{~Hz})$ signal preceding $\sim 5-6 \mathrm{~s}$ the explosion. Infrasonic waveforms were mostly asymmetric with a sharp compressive (5-106 Pa) onset, followed by a small long-lasting rarefaction phase. Regardless of the pressure amplitude, the ratio between the positive and negative phases was constant. These waveform characteristics closely resembled blast waves. Infrared imagery showed an apparent cold spherical front $20 \mathrm{~m}$ thick, which moved between 342 and $405 \mathrm{~m} / \mathrm{s}$ before the explosive hot gas/fragments cloud. We interpret this cold front as that produced by the vapor condensation induced by the passage of the shock front. We suggest that violent strombolian activity at Yasur was driven by supersonic dynamics with gas expanding at 1.1 Mach number inside the conduit. Citation: Marchetti, E., M. Ripepe, D. Delle Donne, R. Genco, A. Finizola, and E. Garaebiti (2013), Blast waves from violent explosive activity at Yasur Volcano, Vanuatu, Geophys. Res. Lett., 40, doi:10.1002/2013GL057900.

\section{Introduction}

[2] Volcano acoustics is providing important constraints on the explosive time history and eruption dynamics, and since its first applications, it is now widely applied worldwide on active volcanoes [e.g., Johnson and Ripepe, 2011; Fee and Matoza, 2013]. Being unaffected by the cloud cover and suffering limited attenuation in the atmosphere, infrasound $(<20 \mathrm{~Hz})$ is also used for event detection at medium-range distances from the source $(<10 \mathrm{~km})$ and to evaluate the intensity and duration of explosive events [e.g., Marchetti et al., 2009].

[3] Volcano acoustics generally assumes a linear theory of sound [Lighthill, 1978] to explain different source mechanisms of a large variety of explosive activity, from strombolian to vulcanian up to subplinian events [e.g., Johnson and Ripepe, 2011].

[4] However, it is possible that in rapid and violent volcanic explosions, similar to nuclear or chemical cases, linear

\footnotetext{
${ }^{1}$ Dipartimento di Scienze della Terra, Università degli Studi di Firenze, Firenze, Italy.

${ }^{2}$ Dipartimento di Scienze della Terra e del Mare, Università degli Studi di Palermo, Palermo, Italy.

${ }^{3}$ Laboratoire GéoSciences Réunion, Université de la Réunion, IPGP, Saint-Denis, France.

${ }^{4}$ Vanuatu Meteorology and Geohazards Department, Port Vila, Vanuatu.

Corresponding author: E. Marchetti, Dipartimento di Scienze della Terra, Università degli Studi di Firenze, Via G. La Pira, 4, IT-50121 Firenze, Italy. (emanuele.marchetti@unifi.it)

(C)2013. American Geophysical Union. All Rights Reserved. 0094-8276/13/10.1002/2013GL057900
}

analyses of infrasound might be limited by nonlinear dynamics [Garces et al., 2013]. In such cases, a shock front generated by the supersonic pressure release in a confined small volume propagates as blast wave. Blast waves are characterized by the sharp compressive onset defined by the leading shock front and by a longer-lasting rarefaction wave of smaller amplitude that forms immediately behind the shock front [Reed, 1977; Needham, 2010].

[5] Unlike in linear acoustics, which predicts in a 3-D space symmetrical acoustic waveforms, blast waves maintain their asymmetrical shape for large distance from the source and only eventually evolve into N-shape waves [Needham, 2010]. Thus, when propagation velocity of a blast wave decays to that of the sound [Kinney, 1962], its asymmetric (or N-shape at larger distance) waveform is the evidence of nonlinear dynamics of the source process.

[6] Up to now, shock fronts for vulcanian events traveling at supersonic propagation velocities in the plume [Nairn, 1976] or immediately above the vent [Yokoo and Ishihara, 2007] have been only observed visually but never reported directly from pressure records.

[7] Direct measurement of propagation velocity is, in fact, strongly limited by the dramatic attenuation of blast waves with distance, which corresponds to a reduction in propagation velocity [Kinney, 1962]; thus, even near-source sensors $(\sim 100 \mathrm{~m})$ are already too far away to detect a supersonic moving front. In this study, we present evidence of blast waves associated with violent explosive activity at Yasur Volcano, which are supported by the analysis of thermal images.

\section{Explosive Activity and Geophysical Deployment}

[8] Explosive activity of Yasur Volcano in the Vanuatu archipelago, southwest Pacific, spans typically from persistent strombolian to vulcanian [Nabyl et al., 1997]. This explosive activity is a prolific source of powerful infrasound recorded as far as $600 \mathrm{~km}$ of distance [Le Pichon et al., 2005]. At the time of the experiment in July/August 2008, the activity was characterized by frequent violent strombolian events from three active vents located within two craters (Figure 1). Explosions were typically violent strombolian, ejecting meter-sized bombs, together with less frequent but sustained ash emissions, lasting up to $20 \mathrm{~s}$ and reaching heights of several hundreds of meters. Two vents (SW and SE in Figure 1a) were active within the southern crater and produced ash-rich and scoria-rich explosions, respectively. A third single vent $(\mathrm{N})$ was active within the northern crater. The activity at the SE and $\mathrm{N}$ craters was very strong and frequent with a mean explosive rate of $\sim 60$ explosions per hour, while explosions at the SW vent were less frequent and weaker.

[9] This activity was recorded with a four-element small aperture $(150 \mathrm{~m}$ ) infrasound array (IAR), deployed at $\sim 700 \mathrm{~m}$ from the active vents, and an infrasonic station (ITS), deployed on the crater rim (Figure 1a). Honeywell ${ }^{\mathrm{TM}}$ 

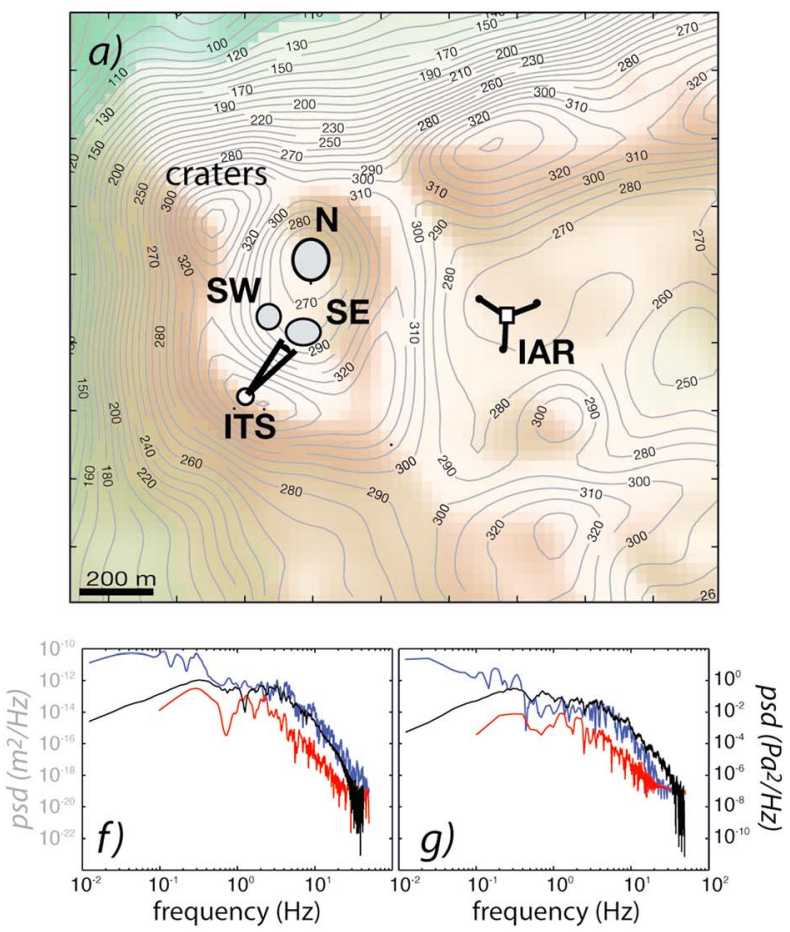
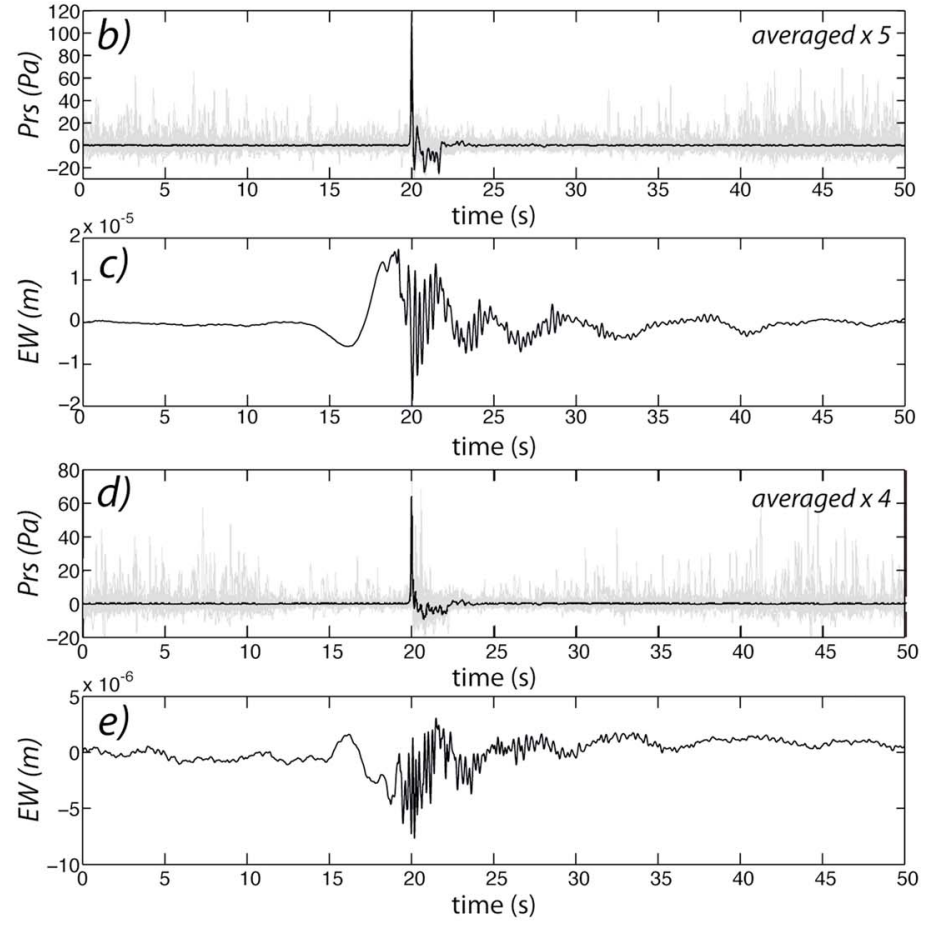

Figure 1. (a) Digital elevation model of Yasur Volcano, Tanna Island, Vanuatu, showing the position of IAR and ITS. The three active vents are shown in gray, while black lines indicate the array geometry at IAR and targeting of the FLIR A20 thermal camera operated at ITS. Raw (gray) and averaged (black) infrasonic waveforms for explosions from (b) SE and (c) $\mathrm{N}$ vents. Averaged ground displacement (no filtering has been applied) shows a remarkable low-frequency $(\sim 0.1-0.3 \mathrm{~Hz})$ component both for the (d) SE and (e) N vents. Pressure and seismic signals have been corrected for the source-to-receiver travel time. Power spectral density of averaged signals associated with the (f) SE and (g) N indicates a frequency of $0.33 \mathrm{~Hz}$ for the pressure wave (black) associated with both craters. Ground displacement (blue) is characterized by two frequency components, one at $3 \mathrm{~Hz}$ associated with the ground couple wave and the other at $0.1-0.3 \mathrm{~Hz}$ triggered by the explosive source process. The red line shows the power spectral density of seismic noise before explosions.

differential pressure transducers (DC001NDR5), with a sensitivity of $10 \mathrm{mV} / \mathrm{Pa}$ in the frequency range of $0.01-50 \mathrm{~Hz}$ and maximum excess pressure of $500 \mathrm{~Pa}$ peak-to-peak, were used as infrasonic sensors. A Guralp CMG/40 T seismometer, with eigenperiod of $30 \mathrm{~s}$, was colocated with the central element of the array. All data were collected at $100 \mathrm{~Hz}$ with Guralp ${ }^{\mathrm{TM}} \mathrm{CMG} / \mathrm{DM} 24$ digitizers with GPS timing.

[10] The thermal videos of explosive activity from SE vent were collected from ITS (Figure 1) with an FLIR A20 thermal camera at $50 \mathrm{~Hz}$. The $34^{\circ} \times 25^{\circ}(9.2 \mathrm{~mm})$ optical lens allowed a complete view of the southern crater and provided a thermal record of the explosion up to $\sim 160 \mathrm{~m}$ height above the vent. Time synchronization of the camera was achieved by GPS receiver.

\section{Infrasonic Activity}

[11] Infrasonic transients were located using the multichannel correlation method [e.g., Ripepe et al., 2007], which allowed separating signal from noise in terms of back azimuth, excess pressure, and propagation velocity. We thus extracted and analyzed $\sim 3000$ explosive events, limiting our analysis to explosions from the SE and $\mathrm{N}$ vents, which were more frequent and energetic than explosions at the SW vent (Figure 1a). Besides, being the back azimuth of the SW vent $\left(267-273^{\circ} \mathrm{N}\right)$ similar to SE vent $\left(262-269^{\circ} \mathrm{N}\right)$, the removal of the SW events from the data set was also based on the amplitude of the acoustic pressure ( $>1 \mathrm{~Pa}$ at the array) and, whenever possible, on the visual observation of the activity. These criteria allowed identifying, between 31 July and 3 August, 2008, 1959, infrasonic and seismic transients for the SE vent (Figure 1b), and 808 events for the $\mathrm{N}$ vent (Figure 1d).

[12] Infrasonic waveforms, from both the SE and N craters, were highly stable in time, leading to a robust averaged signal for each explosive vent (Figures $1 \mathrm{~b}$ and $1 \mathrm{~d}$ ). The mean correlation coefficient between all the single events and the average waveforms exceeded 0.8 for both the vents. The strong waveform stability pointed to a repetitive source mechanism very stable in time and space. Averaging the waveforms disclosed similarities at a small scale in both cases, and the presence of three separate phases is underlined by different color bands in Figure 2. A first, very sharp positive peak of short $(\sim 0.2 \mathrm{~s})$ duration was followed by a longer-lasting $(\sim 2 \mathrm{~s})$ negative phase merging in a final positive weak compressive phase lasting $\sim 1.5 \mathrm{~s}$. The mean peak pressure amplitudes (at $700 \mathrm{~m}$ ) were $24 \mathrm{~Pa}$ for the $\mathrm{SE}$ and $18 \mathrm{~Pa}$ for the $\mathrm{N}$ crater, while the duration of the first pressure pulse was 0.2 and $0.15 \mathrm{~s}$ for the SE and $\mathrm{N}$ crater, respectively. In both the cases, although the amplitude of the peak pressure can vary significantly (more than 1 order of magnitude from 5 to $106 \mathrm{~Pa}$ ) among explosions from the same vent, the duration of the whole signal $(3.5 \mathrm{~s})$ as well as that of the first pressure pulse and the negative phase were very stable (Figure 2). In addition, all the infrasonic signals shared secondary pressure peaks very stable in time (Figure 2). This waveform stability at the small details scale is the evidence of the reliability of the criteria used to separate acoustic waves generated by the same source. 

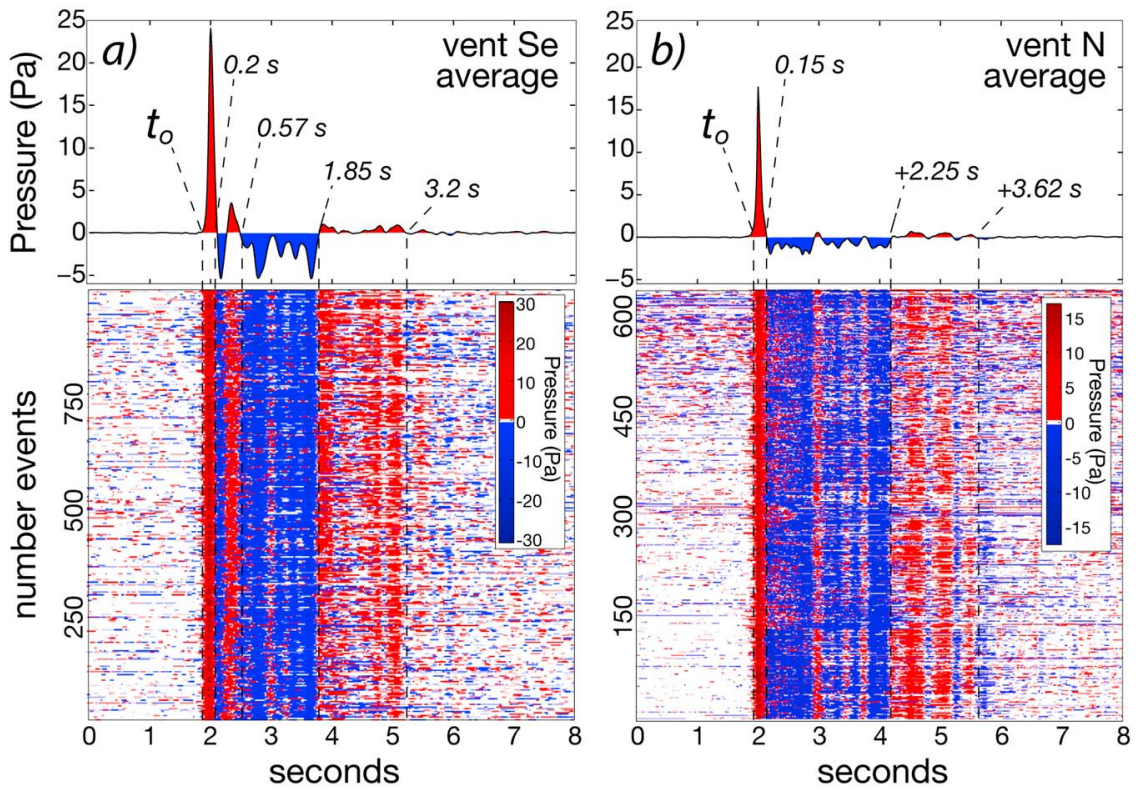

Figure 2. (top) Averaged infrasonic waveforms and (bottom) the alignment of infrasonic transients for explosive events at (a) SE and (b) N vents. Positive (red) and negative (blue) amplitudes highlight the strong stability of the pressure waveforms features, regardless of the variations $(5-106 \mathrm{~Pa})$ in the peak pressure.

\section{Very Long Period Seismic Signal}

[13] Seismic signals associated with explosions at the three vents had durations of 20-30 s and were characterized by emergent onset heavily contaminated by ocean microseisms. Given the large stability of the infrasonic waveforms, seismic signals were aligned according to the infrasonic onsets (Figures 1c and 1e) to enhance the explosive component of the seismic waveform. The averaging for each crater has the property of increasing the signal-to-noise ratio and reducing the effect of seismic tremor and oceanic microseism. For both the SE and N vents, the averaged seismic ground displacement was very stable and enhanced a high-frequency component at $\sim 3 \mathrm{~Hz}$ overimposed to a very long period oscillation $(0.1-0.3 \mathrm{~Hz})$.

[14] Seismic displacement related to explosions from SE vent (Figure 1c) had 4 times higher amplitude $\left(\sim 2 \times 10^{-5} \mathrm{~m}\right)$ than events from $\mathrm{N}$ vent $\left(0.5 \times 10^{-5} \mathrm{~m}\right)$ (Figure $\left.1 \mathrm{e}\right)$. In both the cases, the high-frequency component at $3 \mathrm{~Hz}$ was recorded at the same time as the pressure transient (Figures 1b-1e), suggesting that it was probably produced by the groundcoupled pressure wave. In both the cases, the very long period signal clearly preceded the explosive onset of $\sim 5-6 \mathrm{~s}$. The onset of the very long period oscillation was quite clear on the seismic displacement associated with the SE vent (Figure 1c). This was most probably due to the larger number of signals averaged for the SE (1959) than for the $\mathrm{N}$ vent (808), resulting in a larger attenuation of noise. However, in both cases, the averaging showed how the oscillation was induced by the explosion, and it did not result from the constructive interference of oceanic microseism that was actually recorded in almost the same frequency content.

\section{Thermal Analysis of Explosive Dynamics}

[15] The dynamics of the explosive activity was analyzed from infrared thermal videos collected at $50 \mathrm{~Hz}$. The time evolution of the gas-ash plume emission was obtained from the frame-by-frame temperature difference (see Delle Donne and
Ripepe [2012] for details), because it allowed tracking the plume dynamics in terms of temperature changes (Figure 3a).

[16] Thermal image recorded a sharp temperature drop of $\sim 5^{\circ} \mathrm{C}$, spherically propagating as a cold front $\sim 20 \mathrm{~m}$ thick. This preceded a temperature increase due to the expansion of hot cloud of gas, ash, and lava fragments, which propagated into the atmosphere as a hot front.

[17] We infer that this cold thermal phase is generated by a compressive wavefront that causes instantaneous vapor condensation, triggered by the pressure increase at constant temperature. $\mathrm{H}_{2} \mathrm{O}$ molecules are strongly attenuating thermal infrared by molecular rotations and vibrations, thus resulting into an increased absorption of the infrared thermal radiation coming from the background hot crater wall. This phenomenon was not always visible in the thermal images, and it possibly depended on the thermal radiation of the background hot material, atmospheric conditions, and/or pressure gradient.

[18] This apparent cold thermal phase was also recorded by the infrared radiometer deployed at ITS (Figure 1a), as a small but clear thermal drop of $\sim 1^{\circ}$ with a duration of $\sim 0.2 \mathrm{~s}$ (Figure $3 \mathrm{c}$ ).

[19] To evaluate the propagation velocity of these thermal phases, we calculated the temperature difference between two consecutive frames along a vertical line located in the center of the vent NE (Figure 3b). Using this method, we found that the apparent cold front was propagating from the vent (Figure 3a) with a vertical velocity of $341-403 \mathrm{~m} / \mathrm{s}$ (Figure $3 b$ ). This range in the propagation front velocities (mean value of $372 \mathrm{~m} / \mathrm{s}$ ) was related to our uncertainty in estimating the explosive center within a confidence interval of $\pm 30 \mathrm{~m}$ using a topographic survey.

[20] At ambient pressure, these velocities were consistent with a sound speed $c=\sqrt{\gamma R T}$ in the temperature $T$ range between 293 and $373 \mathrm{~K}$, where $\gamma$ is the heat capacity (1.4) of the gas and $R$ is the specific gas constant $(287.058 \mathrm{~J} / \mathrm{kg} \mathrm{K})$ for dry air. However, if we consider ambient temperature conditions of $20^{\circ} \mathrm{C}(293 \mathrm{~K})$ for the atmosphere above the crater, these velocities suggest propagation of the cold front at supersonic $(>340 \mathrm{~m} / \mathrm{s})$ velocity. 
a)
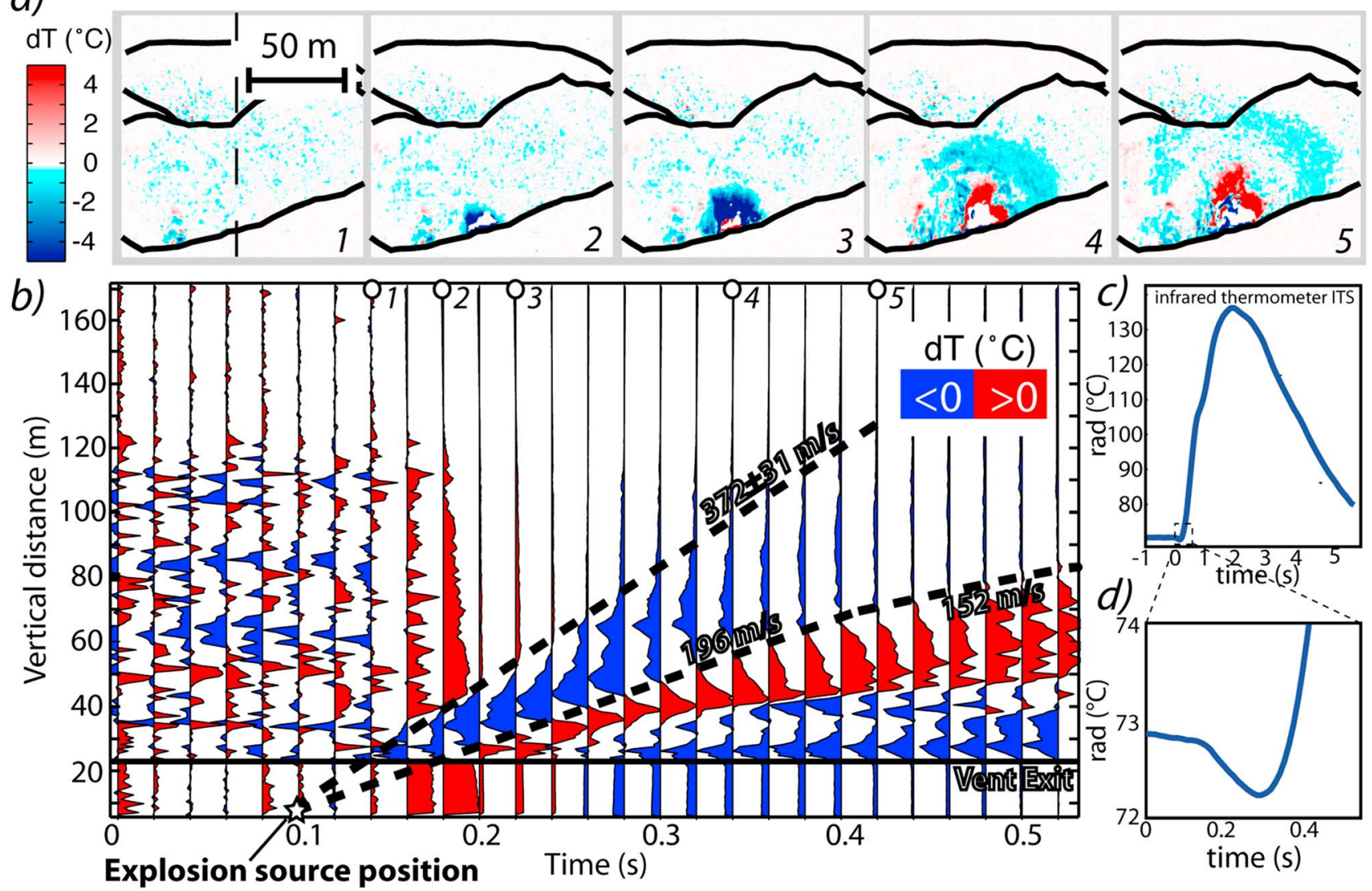

Figure 3. (a) Frame-by-frame thermal difference enhances an apparent cold front spherically radiating from the source during an explosion from SE vent on 1 August 2008. (b) Time evolution of the vertical distribution of the thermal difference shows how the apparent cold (in blue) front, $20 \mathrm{~m}$ large, is moving at a velocity (dashed line) ranging between 341 and $403 \mathrm{~m} / \mathrm{s}$. After $0.04 \mathrm{~s}$, this is followed by the emission of hot gas/fragments cloud (in red), which moves at a velocity of $196 \mathrm{~m} / \mathrm{s}$. (c) Explosion is recorded by the Omega thermal radiometer as a large temperature increase. Moreover, (d) the close-up of the thermal onset shows a small temperature decay, which coincides with the apparent cold front evidenced by the thermal camera shown in Figure 3a.

[21] Shortly after $(0.04 \mathrm{~s}$; two frames in the thermal imagery) the pressure wave, hot material was driven out of the vent by the explosive gas/plume expansion, with a mean upward exit velocity of $196 \mathrm{~m} / \mathrm{s}$ that rapidly decelerated down to a value of $152 \mathrm{~m} / \mathrm{s}$ within $\sim 0.25 \mathrm{~s}$.

\section{Blast Wave Evidence}

[22] Infrasound recorded at Yasur Volcano during the 2008 experiment differs significantly from the symmetric waveform of infrasonic transients commonly recorded on volcanoes producing strombolian and vulcanian explosions [e.g., Johnson and Ripepe, 2011; Fee and Matoza, 2013]. The overall strong stability of the infrasonic signal (Figure 2) is likely to be related to a source process. On the other hand, the impressive waveform stability of the secondary group of peaks (Figure 2) might be related to propagation effects, such as reflections within the conduit [Kim and Lees, 2011] and/or diffraction of topography [Matoza et al., 2009; Lacanna and Ripepe, 2013].

[23] However, the asymmetry of the pressure wave resembles the blast waves radiated by chemical and nuclear explosions (Figure 4c). Blast wave recorded near the source is, in fact, characterized by an asymmetric pressure wave, with the compression peak extremely sharp and much larger than the following rarefaction [e.g., Reed, 1977; Needham, 2010].
With increasing distance from the source, this asymmetry is lost and blast waves assume the characteristic symmetric $\mathrm{N}$-wave shape (Figure 4d). This distance is controlled by the excess pressure at the source. For example, in the case of the $10 \mathrm{t}$ of TNT equivalent Sayarim calibration experiment that produced a peak pressure of $7.14 \mathrm{kPa}$ at $351 \mathrm{~m}$ from the source [Gitterman and Hofstetter, 2012], the asymmetry is already lost at a distance of $5181 \mathrm{~m}$ (Figure 4d).

\subsection{The Friedlander Waveform}

[24] A blast wave is an area of pressure expanding supersonically outward from an explosive source, and it has a leading shock front of compressed gases. The blast wave is followed by a blast wind of negative subsonic pressure (Figure 4c), which sucks items back in toward the center. Moreover, the duration of the rarefaction negative phase is proportional to the duration of the positive pressure pulse, regardless of the peak pressure value [Reed, 1977]. This is well described by the Friedlander's equation, which defines the pressure of the blast wave $p(t)$ as a function of time:

$$
p(t)=p_{o} e^{-\frac{1}{\tau}}\left(1-\frac{t}{\tau}\right)
$$

where $p_{\mathrm{o}}$ is the peak overpressure at the source and $\tau$ is the relaxation time representing the time at which the pressure 


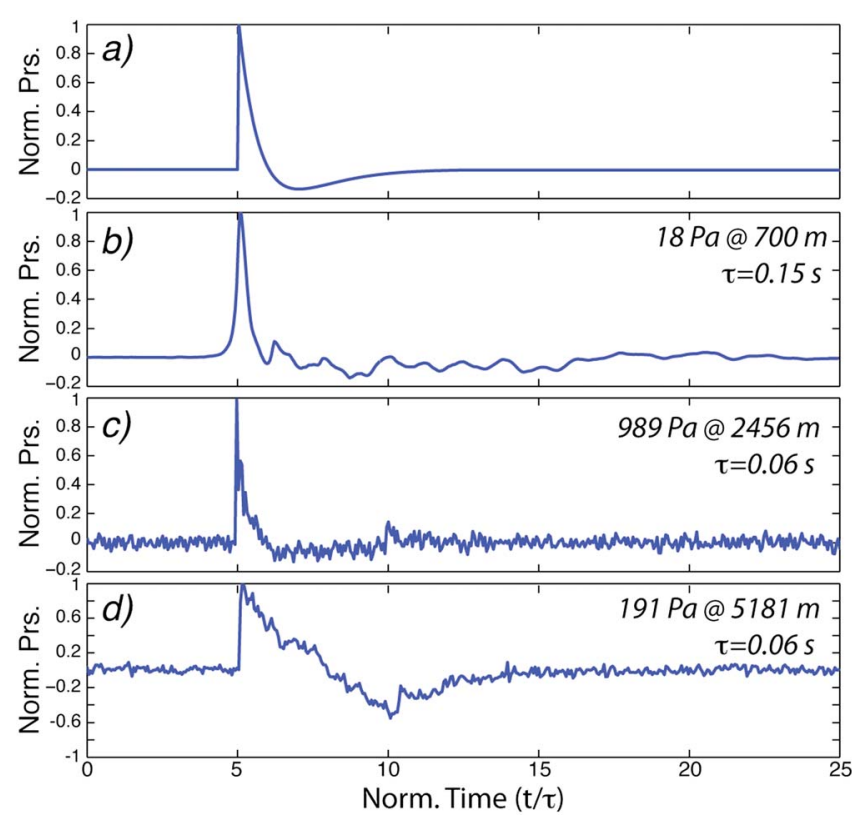

Figure 4. Comparison between (a) theoretical Friedlander waveform, (b) averaged pressure wave at Yasur, and (c and d) blast waves generated by an artificial explosion of $10 \mathrm{t}$ of TNT equivalent during the 2011 Sayarim calibration experiment [Gitterman and Hofstetter, 2012]. The blast wave measured at $2456 \mathrm{~m}$ shown in Figure 4c shows the typical asymmetry predicted by the Friedlander waveform shown in Figure $4 \mathrm{a}$ and calculated from equation 1, assuming a relaxation time $\tau$ of $0.063 \mathrm{~s}$ measured on the raw signal shown in Figure 4c. Asymmetry is lost at the distance of $5181 \mathrm{~m}$ shown in Figure 4d from the source when the blast wave becomes symmetric and assumes the typical $\mathrm{N}$-wave shape. Timescale of the recorded pressure waves has been normalized by different relaxation times. Signals shown in Figures $4 \mathrm{c}$ and $4 \mathrm{~d}$ have been recorded using the same sensors as those used for the Yasur experiment.

first crosses the horizontal axis (before it becomes negative). Friedlander equation shows how the duration of the rarefaction negative peak is proportional to ( $\sim 5$ times) the duration of the first positive compressive peak, regardless of the amplitude of the peak pressure (Figure 4a). Besides, Friedlander's equation also predicts that the amplitude ratio between the positive and negative peaks is constant ( $\sim 7$ times) and independent of the peak overpressure (Figures 2 and $4 \mathrm{a}-4 \mathrm{c}$ ). The average infrasonic waveform of explosions (Figure $4 b$ ) has an amplitude ratio of $\sim 7$ in agreement with the Friedlander equation. Pressure waves recorded at Yasur thus respect the self-similarity principle stated by the Friedlander equation both in terms of amplitude and duration ratios between the positive and negative phases (Figure 4).

\subsection{The Mach Number}

[25] A shock front is a large-amplitude compression wave, which defines a region of abrupt change of pressure, temperature, and density moving at, or above, the velocity of sound. Shock front is usually caused by a body (or fluid) moving supersonically at a velocity $u$ greater than the sound speed $c$ defined in terms of Mach number $M a=u / c>1$. A blast wave is a shock front that expands outward from the explosion center; it is generated by the rapidly expanding gas and implies nonlinear dynamics.

[26] The governing relations for 1-D shock wave theory are described by the Rankine-Hugoniot equations, which define the property changes of a generic fluid across a shock front:

$$
p_{\mathrm{o}}=p_{\mathrm{atm}}\left[1+\frac{2 \gamma}{\gamma+1}\left(M a^{2}-1\right)\right]
$$

where $\gamma=1.4$ is the heat capacity of the dry atmosphere.

[27] Using equation (2), we can calculate the expected Mach number $(M a)$ from the pressure ratio $p_{\mathrm{o}} / p_{\text {atm }}$ at the shock front between the ambient (atmospheric pressure $\left.p_{\text {atm }}=10^{5} \mathrm{~Pa}\right)$ and the shocked state $p_{\mathrm{o}}=1.17 \times 10^{5} \mathrm{~Pa}$, by assuming that overpressure $p_{\mathrm{o}}=p_{\text {atm }}+p_{\text {acu }} \times r$ is equivalent to the acoustic pressure $p_{\text {acu }}(5-106 \mathrm{~Pa})$ recorded at a distance $r=700 \mathrm{~m}$. From equation 2, we estimated a Mach number ranging between 1.01 and 1.28 (mean value $M a=1.1$ ), indicating that the shock front moves at a speed $u$ of 345 and $437 \mathrm{~m} / \mathrm{s}$ (average $u=374 \mathrm{~m} / \mathrm{s}$ ). These values are very close to the mean propagation velocity $(372 \mathrm{~m} / \mathrm{s})$ of the apparent cold front evidenced by thermal imagery (Figure 4).

\section{Discussion and Conclusions}

[28] The violent explosive activity observed at Yasur Volcano during July/August 2008 generated self-similar $(R>0.8)$ infrasonic waveforms, suggesting that explosions are produced by a stationary source process. All the infrasonic signals presented a strong asymmetry, with a sharp positive pressure onset followed by a longer-lasting negative rarefaction phase. Self-similarity and asymmetry of the recorded pressure waveforms resembled blast waves.

[29] During violent explosive dynamics, large quantities of gas are released in a very short time [Needham, 2010]. The gas expands violently forcing out the conduit to the surrounding air. A layer of compressed air forms in front (the shock front) of the gas/fragments cloud. As the gases expand, their pressure drops to atmospheric levels. Thus, the pressure of the compressed air at the blast wavefront reduces with distance from the source. As the expansion continues, pressure falls a little below ambient atmospheric levels because the velocity of the gas causes a partial overexpansion, which is recorded as a negative rarefaction excess pressure (the blast wave). Acoustic signals recorded at Yasur exhibited constant ratio between the positive and negative phases, which fits the Friedland waveform and supports the blast wave model.

[30] Moreover, thermal imagery could detect this pressure wave as soon as it exited the vent as a relative $\sim 20 \mathrm{~m}$ thick cold front, which radiates spherically from the source. This front of relative cold temperature moves before the volcanic hot gas/fragments cloud, demonstrating that acoustic waves are generated by gas expansion within the conduit.

[31] The propagation velocity of the cold front measured by thermal images at the vent ranged between 341 and $403 \mathrm{~m} / \mathrm{s}$, depending on our $\pm 30 \mathrm{~m}$ uncertainty on the source camera slant distance and topography of the crater rim. By assuming supersonic dynamics, the Rankine-Hugoniot relationship for the mean acoustic pressure $(25 \mathrm{~Pa})$ recorded at the array presented a Mach number of 1.1, equivalent to a gas expansion velocity of $374 \mathrm{~m} / \mathrm{s}$. 
[32] Our data thus suggest that explosive activity at Yasur is capable of generating blast waves. The blast waves are expected and well documented for plinian eruptions [Reed, 1987] and have also been reported for vulcanian eruptions [Nairn, 1976; Yokoo and Ishihara, 2007]; however, they have never been recorded during strombolian events. This evidence has a direct consequence on the source modeling of infrasonic transients generated by explosions because it requires nonlinear source dynamics to also explain smallscale (volcanic explosivity index $<2$ ) explosive processes. Till date, nonlinear dynamics of sound had been neglected, and our recordings point out the need to critically address the linear theory assumption when inferring source properties by infrasonic signals.

[33] Acknowledgments. We thank the logistical support provided in Vanuatu by researchers from the French project ANR-Arc-Vanuatu. E. M. was supported by the European Union ARISE FP7 project (GA 284387). We thank Robin Matoza and an anonymous referee for the constructive critical comments of the manuscript.

[34] The Editor thanks Robin Matoza and an anonymous reviewer for their assistance in evaluating this paper.

\section{References}

Delle Donne, D., and M. Ripepe (2012), High-Frame Rate Thermal Imagery of Strombolian Explosions: Implications for Explosive and Infrasonic Source Dynamics, J. Geophys. Res., 117, B09206, doi:10.1029/ 2011JB008987.

Fee, D., and R. S. Matoza (2013), An overview of volcano infrasound: From Hawaiian to Plinian, local to global, L. Volcanol. Geoth. Res., 249 123-139, doi:10.1026/j.volgeores.2012.09.002.

Garces, M. A., D. Fee, and R. Matoza (2013), Volcano Acoustics, Chapter 16, in Modeling Volcanic Processes: The Physics and Mathematics of Volcanism, edited by S. A. Fagents, T. K. P. Gregg, and R. M. C. Lopes, Cambridge Univ. Press, Cambridge, U. K.

Gitterman, Y., and R. Hofstetter (2012), GT0 explosion sources for IMS infrasound calibration: charge design and yield estimation from near-source observations, Pure Appl. Geophys., doi:10.1007/s00024012-0575-4

Johnson, J. B., and M. Ripepe (2011), Volcano infrasound: A review, J. Volcanol. Geoth. Res., 206, 61-69, doi:10.1016/j.jvolgeores.2011.06.006.

Kim, K., and J. M. Lees (2011), Finite-difference time-domain modeling of transient infrasonic wavefields excited by volcanic explosions, Geophys. Res. Lett., 38, L06804, doi:10.1029/2010GL046615.

Kinney, G. F. (1962), Explosive Shocks in Air, pp. 198, MacMillan, New York.

Lacanna, G., and M. Ripepe (2013), Influence of near-source volcano topography on the acoustic wavefield and implication for source modeling, J. Volcanol. Geoth. Res., 250, 9-18, doi:10.1016/j.jvolgeores.2012.10.005.

Le Pichon, A., E. Blanc, D. P. Drob, S. Lambotte, J. X. Dessa, M. Lardy, P. Bani, and S. Vergniolle (2005), Infrasound monitoring of volcanoes to probe high altitude winds, J. Geophys. Res., 110, D13106, doi:10.1029/2004JD005587.

Lighthill, J. (1978), Waves in Fluids, pp. 504, Cambridge Univ. Press., U. K. Marchetti, E., M. Ripepe, A. J. L. Harris, and D. Delle Donne (2009), Tracing the differences between Vulcanian and Strombolian explosions using infrasonic and thermal radiation energy, Earth and Planet. Sci. Lett., 279, 273-281, doi:10.1016/j.eps1.2009.01.004.

Matoza, R. S., M. A. Garces, B. A. Chouet, L. D'Auria, M. A. H. Hedlin, C. De Groot-Hedlin, and G. P. Waite (2009), The source of infrasound associated with long-period events at Mount St. Helens, J. Geophys. Res., 114, B04305, doi:10.1029/2008JB006128.

Nabyl, A., J. Dorel, and M. Lardy (1997), A comparative study of low-frequency seismic signals recorded at Stromboli volcano, Italy, and at Yasur volcano, Vanuatu, New Zealand J. Geol Geophys., 40(4), 549-558, doi:10.1080/00288306.1997.9514783.

Nairn, I. A. (1976), Atmospheric shock waves and condensation clouds from Ngauruhoe explosive eruptions, Nature, 259, 190-192, doi:10.1038/ $259190 \mathrm{a} 0$.

Needham, C. E. (2010), Bast Waves, 339 pp., Springer, Heidelberg.

Reed, J. W. (1977), Atmospheric attenuation of explosion waves, J. Acoust. Soc. Am. 61, 39-47.

Reed, J. W. (1987), Air pressure waves from Mount St. Helens eruptions, J. Geophys. Res., 92(D10), 11,979-11,992.

Ripepe, M., E. Marchetti, and G. Ulivieri (2007), Infrasonic monitoring at Stromboli volcano during the 2003 effusive eruption: Insights on the explosive and degassing process of an open conduit system, J. Geophys. Res., 112, B09207, doi:10.1029/2006JB004613.

Yokoo, A., and K. Ishihara (2007), Analysis of pressure waves observed in Sakurajima eruption movies, Earth Planets Space, 59, 177-182. 